\title{
The ORC1 homolog orp1 in fission yeast plays a key role in regulating onset of S phase
}

\author{
Beata Grallert $^{1}$ and Paul Nurse ${ }^{2}$ \\ Imperial Cancer Research Fund, Cell Cycle Laboratory, London WC2A 3PX UK
}

In a screen for new cell-cycle genes in Schizosaccharomyces pombe we have isolated cdc30, which is identical to orp1, a putative homolog of the Saccharomyces cerevisiae ORC1 gene. Analysis of the temperaturesensitive orp 1-4 and the orp1 $1 \mathrm{mutants}$ indicates that orp1 is required at the onset of $S$ phase for an early step of DNA replication. Orp1p is found in the nucleus and is present at a constant level throughout the cell cycle. Genetic interactions occur between orp1 and $c d c 18$ and $c d c 21$ (an MCM homolog). Orp1p forms protein complexes with both cdc18p and cdc21p in vivo, suggesting that interactions between these proteins and ORC are important for controlling the initiation of DNA replication at the onset of S phase. The orp1 gene is also required for the control that prevents entry into mitosis in the absence of DNA replication, suggesting a role for ORC in this checkpoint pathway.

[Key Words: ORC1 homolog; fission yeast; S-phase onset; checkpoint]

Received May 14, 1996; revised version accepted August 20, 1996.

Control of the $\mathrm{G}_{1}$ - to S-phase transition is an important regulatory point in the eukaryotic cell cycle, because successful replication of the chromosomes is a prerequisite for producing two normal daughter cells at division. Understanding how $\mathrm{S}$ phase is regulated requires characterization of the molecular mechanism that carries out DNA replication, and also a description of the regulatory processes that ensure that replication occurs once and only once every cell cycle. Here we characterize a fission yeast gene that may be part of the link between the mechanism of DNA replication and overall cell-cycle control.

Much progress has been made in describing the components of the eukaryotic DNA replication machinery using in vitro model systems, primarily SV40, and genetic systems, primarily budding yeast. One component of particular interest for understanding the initiation of replication is the complex of six proteins called the origin recognition complex (ORC) purified from budding yeast (Bell and Stillman 1992). The genes encoding these proteins have been cloned (Bell et al. 1993, 1995), and it has been demonstrated that the frequency of initiation events decreases in orc mutants (Fox et al. 1995; Liang et al. 1995). The ORC complex binds origins throughout the cell cycle (Diffley and Cocker 1992; Diffley et al. 1994), and therefore changes in origin binding of the six proteins making up the ORC complex seem unlikely to

${ }_{1}^{1}$ Present address: Institute for Cancer Research, Department of Biophysics, Montebello, 0310 Oslo, Norway.

${ }^{2}$ Corresponding author. control the initiation of replication. The genomic footprint on replication origins changes prior to replication as a result of the formation of a prereplicative complex (Diffley et al. 1994). Components of this prereplicative complex additional to the six proteins making up the ORC have yet to be defined. Homologs of two components of the ORC complex have been identified in a number of organisms: ORC1 homologs have been found in Kluyveromyces lactis, human cells, and Schizosaccharomyces pombe (Gavin et al. 1995; Muzi-Falconi and Kelly 1995), and ORC2 homologs in Arabidopsis thaliana, Caenorhabditis elegans, human cells (Gavin et al. 1995), Xenopus laevis (Carpenter et al. 1996), fruit fly (Gossen et al. 1995), and S. pombe (Leatherwood et al. 1996). The existence of these homologs suggests that the ORC complex is likely to be conserved during evolution.

In fission yeast $c d c 18$ is a crucial regulator of the initiation of DNA replication. The levels of $c d c 18$ mRNA and of $\mathrm{p} 65^{\mathrm{cdc} 18}$ encoded by $c d c 18$ both increase prior to entry into S phase (Kelly et al. 1993; Nishitani and Nurse 1995; Muzi-Falconi et al. 1996). In the absence of $c d c 18$ the cells cannot replicate their DNA, blocking initially with a $1 C$ DNA content and then proceeding to mitosis. This last observation indicates that $\mathrm{p} 65^{\mathrm{cdc} 18}$ is also necessary to prevent mitosis until S phase is complete (Kelly et al. 1993). Importantly, overexpression of the $c d c 18$ gene is sufficient to drive cells into $S$ phase in the absence of mitosis and without continuing protein synthesis (Nishitani and Nurse 1995), indicating that p65 ${ }^{\mathrm{cdc} 18}$ is likely to play a rate determining role in the onset of $S$ phase. 
The regulatory processes governing DNA replication ensure that $S$ phase is confined to a specific phase of the cell cycle and is coordinated with other major cell-cycle events. Two main control mechanisms are emerging that have been proposed to limit DNA replication to once per cell cycle. One is the global cell-cycle control acting over entry into $S$ phase that involves cyclin-dependent kinases (CDKs). Identification of a role of CDKs in ensuring that there is only one S phase per cell cycle was made in fission yeast. Deletion of the $c d c 13$ gene, which encodes the major mitotic B cyclin in fission yeast, leads to repeated rounds of replication without intervening mitoses, suggesting that the presence of the cdc2/cyclinB protein kinase prevents a $G_{2}$ cell from undergoing another $S$ phase (Hayles et al. 1994). Overexpression of the rum1 gene also results in repeated rounds of replication (Moreno and Nurse 1994) as a consequence of $\mathrm{p} 25^{\mathrm{rum} 1}$ acting as an inhibitor of the cdc2/cyclinB complex (Correa-Bordes and Nurse 1995; Martin-Castellanos et al. 1996). The second control mechanism has emerged from experiments with Xenopus extracts that have identified an activity required to "license" DNA, such that replication occurs only once in each cell cycle. Several lines of evidence suggest that proteins of the MCM family may have a role in this licensing control. MCM genes were first identified in budding yeast in genetic screens for mutants that lose minichromosomes at high frequency (Maine et al. 1984). The MCM proteins show a cell cycle-dependent localization in the yeast nucleus (Hennessy et al. 1990; Yan et al. 1993; Dalton and Whitbread 1995), and have been identified in a large number of organisms (for review, see Chong et al. 1996). In multicellular eukaryotes, MCM proteins are generally found to be nuclear throughout the cell cycle, although they show cell cycle-dependent chromatin binding (Kimura et al. 1994; Chong et al. 1995; Kubota et al. 1995; Madine et al. 1995; Todorov et al. 1995; Coué et al. 1996; Fujita et al. 1996; Krude et al. 1996). The exact role of MCMs and the mechanism by which they contribute to proper regulation of $S$ phase is as yet unclear.

In this paper we describe the isolation of $c d c 30$ from fission yeast and show that it is identical to orp1, a gene proposed to encode a homolog of ORCl. Analysis of the phenotypes of temperature-sensitive and deletion mutants of orp1 indicates that the gene is required at an early step of DNA replication and is also necessary to restrain mitosis until DNA replication is complete. We show genetic and physical interactions between orp 1 and $c d c 18$, and between orp1 and $c d c 21$, an MCM4 homolog in fission yeast, and propose that these interactions are important for linking the initiation of DNA replication to overall cell-cycle control.

\section{Results}

Isolation of mutants acting at $G_{1} / S$

To identify new genes acting at the $G_{1} / S$-phase $\left(G_{1} / S\right)$ control in fission yeast we screened a bank of 2000 temperature-sensitive lethal mutants for those that arrested at the $G_{1} / S$ transition. We isolated 172 mutants displaying an elongated phenotype at the restrictive temperature, and 65 of these were found by DAPI staining to arrest with a single interphase nucleus. These were subjected to FACS analysis to identify those which arrested with a 1C DNA content or close to a 1C DNA content, and 12 such mutants were isolated. Complementation analysis between these 12 mutants and mutants of previously described genes required at the $G_{1} / S$ transition identified novel alleles of $c d c 6, c d c 23$, and $c d c 20$ and five new genes. The mutants in the five new genes showed various phenotypes: Two arrested with a 1C DNA content, two showed S-phase defects, and one arrested with a mixed population of cells having $1 \mathrm{C}$ and $2 \mathrm{C}$ DNA contents. One of the mutants that arrested with a 1C DNA content, $c d c 30-4$, was chosen for further study because it showed uniform first cell-cycle arrest. Cell division stopped after a cell number doubling, and cells became elongated with a uniform 1C DNA content (Fig. 1).

\section{cdc30-4 arrests early in the cell cycle}

To map the cell-cycle arrest point of the $c d c 30-4$ mutant more accurately we carried out a reciprocal shift experiment with a hydroxyurea block. DNA replication in $c d c 30^{+}$and $c d c 30-4$ cells was inibited using hydroxyurea at $25^{\circ} \mathrm{C}$, the permissive temperature for $c d c 30-4$. The cells were then shifted to the restrictive temperature $36^{\circ} \mathrm{C}$, and the hydroxyurea removed. The two cultures underwent cell division with the same kinetics (Fig. 2A), indicating that $c d c 30-4$ functions either upstream or at the hydroxyurea block. The same result was obtained when the cells were kept at $36^{\circ} \mathrm{C}$ during the last hour of the hydroxyurea block to ensure that the temperature-sensitive protein was fully denatured before re-
A
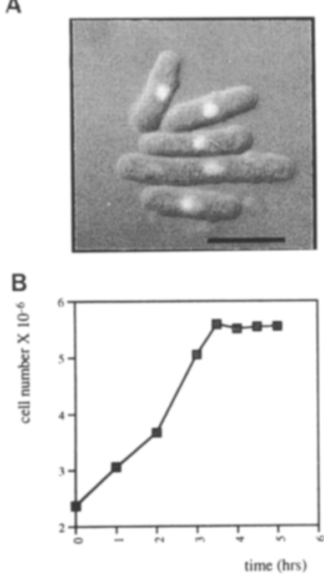
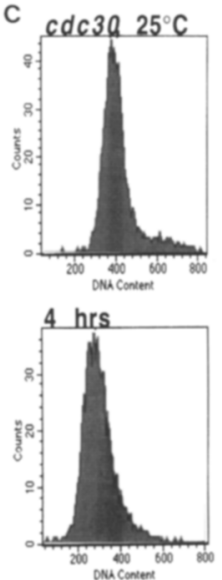
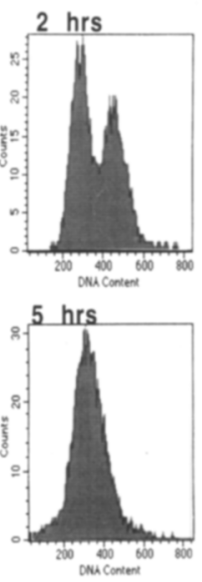

Figure 1. $c d c 30-4$ arrests with a 1C DNA content. $(A) c d c 30-4$ cells after $5 \mathrm{hr}$ at the restrictive temperature. $(B)$ Cell number increase of $c d c 30-4$ cells upon shift to $36^{\circ} \mathrm{C}$. $(C)$ FACS analysis of $c d c 30-4$ cells at permissive temperature and 2,4 , and $5 \mathrm{hr}$ after shift to the restrictive temperature. 


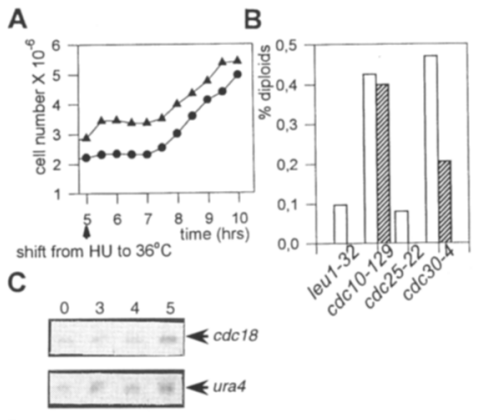

D

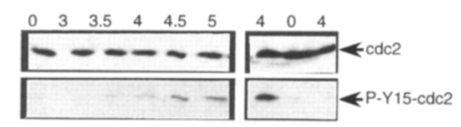

$\mathrm{E}$

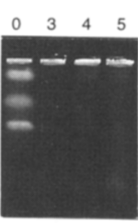

$\mathrm{F}$

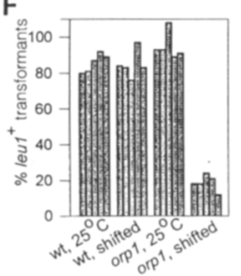

Figure 2. $c d c 30-4$ arrests at an early stage of $S$ phase. $(A)$ Cell number increase in a hydroxyurea reciprocal shift experiment. $(\mathbf{\Delta})$ cdc30-4 cells; $(\mathbf{O})$ cdc $30^{+}$cells. Cells were arrested with 12 mM hydroxyurea at the permissive temperature of $25^{\circ} \mathrm{C}$, then shifted to the restrictive temperature of $36^{\circ} \mathrm{C}$ and the hydroxyurea removed. $(B)$ cdc30-4 cells can conjugate from the arrest point. cdc30-4, cdc10-129, cdc25-22, and leu1-32 cells were mixed with mat2-102 ade6- cells to determine the conjugation frequency as described in Materials and Methods. Open bars: incubated at $25^{\circ} \mathrm{C}$, hatched bars: shifted to $36^{\circ} \mathrm{C}$ for $4 \mathrm{hr}$ and then to $32.5^{\circ} \mathrm{C}$ to allow conjugation. $(\mathrm{C})$ Level of $c d c 18$ message in $c d c 30-4$. RNA was isolated from cells shifted to $36^{\circ} \mathrm{C}$ for 0,3 , 4 , and $5 \mathrm{hr}$. ura 4 transcript level was measured as loading control. (D) Tyrosine phosphorylation of cdc2 in $c d c 30-4$. Protein extracts were prepared from cells shifted to $36^{\circ} \mathrm{C}$ for $0,3,3.5,4$, 4.5 , and $5 \mathrm{hr}$ for Western blotting with $\alpha$-cdc2 (upper lanes) and $\alpha$-tyrosine phosphorylated cdc2 (lower lanes). Panel on left shows $c d c 30-4$ extracts, panel on right shows $c d c 25-22$ (lane 1) and cdc10-129 (lanes 2,3) incubated at $36^{\circ} \mathrm{C}$ for 4,0 , and $4 \mathrm{hr}$, respectively, to demonstrate the specificity of the antibody for the tyrosine phosphorylated form. $(E)$ PFGE of chromosomes prepared from orp1-4 (cdc30-4) cells $0,3,4$, and $5 \mathrm{hr}$ after shift to $36^{\circ} \mathrm{C}$. $(F)$ Plasmid stability in orp1-4. leu1-32 and leu1-32 orp 1-4 cells were transformed with a plasmid carrying one copy of ARS1 and a LEU2 marker (see text). The histogram shows the number of leu ${ }^{+}$cells as a percentage of total cells at the time of shift back to $25^{\circ} \mathrm{C}$.

moval of the hydroxyurea (data not shown). This excludes the possibility that the observed replication and cell division were due to residual activity of the temperature-sensitive protein following shift-up. The reciprocal experiment was also performed when $c d c 30-4$ was incubated at $36^{\circ} \mathrm{C}$ for $4 \mathrm{hr}$ before shift to $25^{\circ} \mathrm{C}$ in the presence and absence of hydroxyurea. However, even the cells shifted to $25^{\circ} \mathrm{C}$ in the absence of hydroxyurea did not undergo cell division within a $5-\mathrm{hr}$ incubation (data not shown), indicating that the $c d c 30-4$ cells cannot rapidly recover from the $36^{\circ} \mathrm{C}$ arrest. This lack of recovery pre- vents a distinction being made as to whether $c d c 30^{+}$ functions upstream or at the hydroxyurea block. From these experiments we conclude that $c d c 30^{+}$functions early in the cell cycle, either before or at the start of $S$ phase.

Cells become committed to the mitotic cycle at the $\mathrm{G}_{1} / \mathrm{S}$ boundary at the control called START. In fission yeast three genes have been found to operate at or before START, $c d c 2, c d c 10$, and res1 (Nurse and Bissett 1981; Tanaka et al. 1992; Caligiuri and Beach 1993). To determine whether the $c d c 30-4$ mutant is committed to the cell cycle at its arrest point, we asked whether such arrested cells were able to conjugate. The conjugation efficiency of $c d c 30-4$ was compared with that of $c d c 10$ 129 , which is able to conjugate from its arrest point in $G_{1}$ (Nurse and Bissett 1981). Arrested cdc30-4 cells form about half as many diploids as $c d c 10-129$, and far more than those formed with the $\mathrm{G}_{2}$-arrested cdc25-22 cells (Fig. 2B). Therefore $c d c 30-4$ appears to arrest before or at the point of commitment to the mitotic cell cycle.

$c d c 10$ is required for the transcriptional activation of genes necessary for the initiation of $S$ phase (Lowndes et al. 1992), including transcription of the cdc18 gene (Kelly et al. 1993|. cdc30-4 arrests with cdc18 mRNA present at a level comparable to that seen in exponentially growing cells (Fig. 2C), suggesting that the cdc30-4 mutant arrests later than $c d c 10-129$. Consistent with this conclusion is the observation that the tyrosine phosphorylated form of $\mathrm{p} 34^{\mathrm{cdc} 2}$ accumulates in cdc30-4 cells $4.5-5 \mathrm{hr}$ after the shift to $36^{\circ} \mathrm{C}$ (Fig. 2D, lower left) when they have all arrested in $\mathrm{G}_{1}$ (Fig. $1 \mathrm{C}$ ). This result is in contrast to a cdc10-129 mutant $4 \mathrm{hr}$ after the shift to $36^{\circ} \mathrm{C}$ when no tyrosine phosphorylated form is detectable (Fig. 2D, lower right; Hayles and Nurse 1995).

Overall, these experiments establish that $c d c 30$ functions early in the cell cycle, close to the point of cellcycle commitment at START and to the onset of S phase.

\section{cdc30 encodes a homolog of ORC1}

The $c d c 30$ gene was cloned by complementation of the temperature-sensitive lethal phenotype using a fission yeast genomic library. The gene encodes a putative protein of 707 amino acids that is $31 \%$ identical to the product of the $S$. pombe cdc18 gene and $30 \%$ identical to the product of the $S$. cerevisiae ORC1 gene. Recently the gene has been isolated independently by Gavin et al. (1995) and Muzi-Falconi and Kelly (1995) as orp1. Furthermore, a temperature-sensitive mutant has been isolated by K. Suto, H. Murakami, and H. Okayama (pers. comm.), which also defines the same gene. Given that the name orp1 has already been used for this gene, from now on we shall use the name orp1 instead of $c d c 30$.

\section{The orp1-4 mutant is defective in DNA replication}

The early arrest point of the orp1-4 (originally $c d c 30-4$ ) mutant suggests a role at the $\mathrm{G}_{1} / \mathrm{S}$ transition. Given the sequence similarity to the $S$. cerevisiae $O R C 1$, we inves- 
tigated whether DNA replication is defective in this mutant. DNA was prepared for pulsed field gel electrophoresis from orp1-4 cells grown at permissive and restrictive temperatures. When the cells were grown at the permissive temperature, the three chromosomes entered the gel and could be separated as three distinct bands. In contrast, when the cells were grown at the restrictive temperature, the chromosomes could not enter the gel (Fig. 2E). This indicates that the topology of the DNA is altered, suggesting that some early stages of the initiation process have occurred at the nonpermissive temperture. Since these cells have an approximately 1C DNA content, this indicates that the orp1-4 mutant has a defect at an early stage of DNA replication.

Several $S$. cerevisiae mutants defective in DNA replication have been reported to lose episomal plasmids at high frequency (Hogan and Koshland 1992; Foss et al. 1993; Micklem et al. 1993; Loo et al. 1995). We examined whether this is also true for the orp1-4 mutant. orp $1^{+}$and orp1-4 cells were transformed with a plasmid carrying one copy of ARS1 and a selectable marker. The transformants were shifted to the restrictive temperature and selection for the plasmid relaxed. After $4 \mathrm{hr}$ at $36^{\circ} \mathrm{C}$ the cells were shifted to the permissive temperature and plated onto appropriate media to determine the rate of plasmid loss. While the temperature shift had no effect on plasmid loss in orp $1^{+}$cells, less than a quarter of the orp $1^{-}$cells retained the plasmid after the 4-hr incubation at $36^{\circ} \mathrm{C}$ (Fig. $2 \mathrm{~F}$ ). This result indicates that the orp1 gene function is required for efficient replication of plasmids.

Synthetic checkpoint defects in orp 1-4 cdc18-K46 and orp 1-4 cdc21-M68 double mutants

Between 3 to $5 \mathrm{hr}$ after shifting the orp1-4 mutant to the restrictive temperature, the cell number increase reached a plateau, and after this time, from 5 to $8 \mathrm{hr}$, cell number increased again (Fig. 3Aa). This increase was due to mitosis and cell division as judged by spindle formation and the appearance of postanaphase arrays (Fig. $3 \mathrm{Ab}, \mathrm{c})$. Despite undergoing mitosis, the cells had still failed to undergo DNA replication, and divided with a 1C DNA content, producing daughter cells with an uneven distribution of DNA (Fig. 3Ac). This so-called "cut" phenotype was eventually exhibited by up to $50 \%$ of the population (Fig. 3A a). This suggests that in addition to being required for DNA replication, the orp1 gene also may have some role in the checkpoint pathway that prevents mitosis until $S$ phase is complete.

This $\mathrm{G}_{1}$ arrest and cut phenotype of the orp $1^{\text {ts }}$ mutant is reminiscent of that observed with $c d c 18 \Delta$. Therefore we asked whether there was a genetic interaction between orp 1 and $c d c 18$. We constructed a double mutant carrying both the temperature-sensitive $c d c 18-K 46$ and orp1-4 alleles. The temperature-sensitive allele $c d c 18$ K46 is leaky, and unlike the full deletion of $c d c 18$ it arrests with an approximately 2C DNA content and fails to enter mitosis (Nasmyth and Nurse 1981). While the orp 1-4 mutant arrests at $\mathrm{G}_{1} / \mathrm{S}$ and only then proceeds
A a

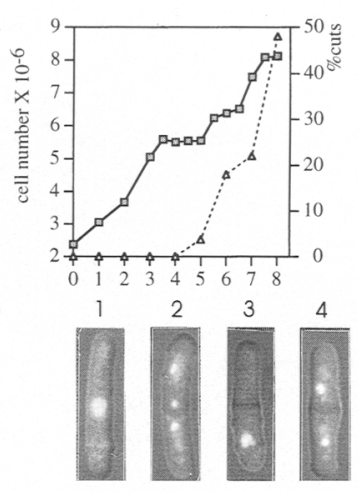

c

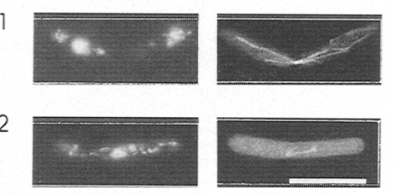

B

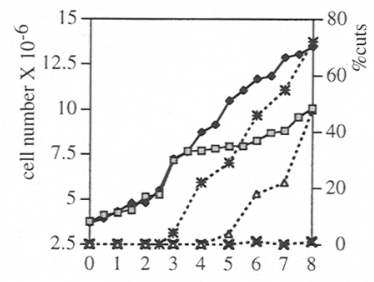

C

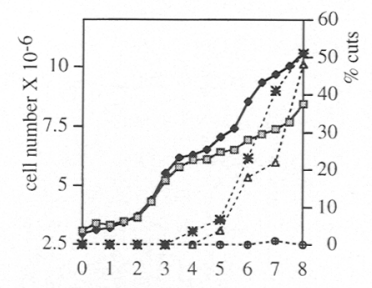

Figure 3. Synthetic checkpoint defect in the double mutants orp 1-4 cdc18-K46 and orp1-4 cdc21-M68. (A) orp1 is required for the checkpoint preventing entry into mitosis until $\mathrm{S}$ phase is complete. (a) Cell number increase (shaded boxes) and percent of cut cells $(\Delta)$ in orp 1-4 following shift to the restrictive temperature. (b) DAPI-stained cells $7 \mathrm{hr}$ after shift up. Cell $\mathrm{l}$ arrested in interphase, cells 2-4 cut. (c) DAPI (left) and tubulin (right) staining of cells $7 \mathrm{hr}$ after shift to the restrictive temperature. Cell 1 shows a postanaphase array, cell 2 contains a mitotic spindle, and chromatin is distributed unevenly. Bar, $10 \mu \mathrm{m} .(B)$ Genetic interaction between orp1 and $c d c 18$. Cell number increase (solid lines) and \% cut cells (dashed lines) after shift to the restrictive temperature. (Shaded boxes) orp1-4; $(\$)$ cdc18-K46 orp $1-4 ;(\triangle)$ percent cuts in orp $\left.1-4 ;\left.\right|^{*}\right)$ percent cuts in $c d c 18-K 46$ orp1-4; $(\times)$ percent cuts in orp1-4 overexpressing $c d c 18^{+} .(C)$ Genetic interaction between orp1 and $c d c 21$. Cell number increase (solid lines) and percent cut cells (dashed lines) after shift to the restrictive temperature. (Shaded boxes) orp1-4; $\mid$ cdc21M68 orp 1-4; $(\triangle)$ percent cuts in orp1-4; $\left({ }^{*}\right)$ percent cuts in $c d c 21$ M68 orp1-4; $(\oplus)$ percent cuts in $c d c 21-M 68$.

slowly to mitosis and cell division, the double mutant proceeds rapidly to mitosis and cell division (Fig. 3B). Overexpression of $c d c 18$ in the orp1-4 mutant rescues the checkpoint defect (Fig. 3B). These observations sug- 
gest that orp 1 and $c d c 18$ might interact in the process that prevents mitosis in the absence of DNA replication.

In addition to the synthetic checkpoint defect of $c d c 18$ and orp1, a genetic interaction was also observed between orp1 and $c d c 21$, which encodes the fission yeast homolog of MCM4 (Coxon et al. 1992). The cdc21-M68 and orp 1-4 mutants are synthetically lethal; at $29^{\circ} \mathrm{C}$ the double mutant is unable to form colonies, unlike the single mutants. Furthermore, the checkpoint phenotype of the cdc21-M68 orp1-4 double mutant at $36^{\circ} \mathrm{C}$ is enhanced, although only a smaller percentage of $1 \mathrm{C}$ cells undergo mitosis (Fig. 3C) compared with the cdc18-K46 orp1-4 double mutant.

These results establish that orp1 plays a role in preventing mitosis when $S$ phase is incomplete, and are suggestive that orp1 may interact with $c d c 18$ and the MCM4 homolog $c d c 21$ in bringing about this checkpoint control.

\section{Characterization of orpls and orpl overexpressing strains}

We deleted the region coding for amino acids 195-607 of orp 1 and replaced it with the $\mathrm{ura}^{+}$gene; the deletion removes the region most highly conserved between cdc18 and ORC1. One of the wild-type copies of the gene was replaced with the deletion construct in a diploid strain homozygous for ura4-D18. When the diploid was sporulated and tetrads analyzed, only two spores were able to form colonies. Both of these were $\mathrm{ura}^{-}{ }^{-}$, showing that the orp1 gene is essential. To analyze the phenotype of the deletion mutant, the diploid was sporulated and the spores inoculated into medium that allows germination of only the spores carrying the deletion. The orp $1 \Delta$ spores germinated and underwent the first cell cycle with a similar kinetics to orp $1^{+}$spores (Fig. 4A), but at later timepoints they underwent cell-cycle arrest. However, unlike the temperature-sensitive orp1-4 mutant, the deletion mutant cells arrested with a 2C DNA content. Furthermore, only a few percent of the cells showed aberrant nuclear morphology indicative of a premature entry into mitosis, even $18 \mathrm{hr}$ after inoculation (Fig. 4A). These results are similar to the findings of Muzi-Falconi and Kelly (1995).

We were concerned that the phenotype of the temperature-sensitive mutant was different from that of the orp1 deletion. The spores carrying the deletion underwent at least one complete normal cell cycle after germination, indicating that the spores might have contained residual orp1 protein carried over from the parental diploid into the spore, masking expression of the deletion phenotype. We therefore constructed a diploid strain heterozygous for the deletion and the temperature-sensitive orp 1-4 allele. Spores derived from this diploid were germinated at the restrictive temperature to inactivate any residual temperature-sensitive orpl protein. The spores carrying the orp $1 \Delta$ arrested in $\mathrm{G}_{1}$ and then proceeded to mitosis primarily with a $1 \mathrm{C}$ DNA content, with over $90 \%$ of cells displaying the cut phenotype $10 \mathrm{hr}$ after inoculation (Fig. 4B). This result confirmed

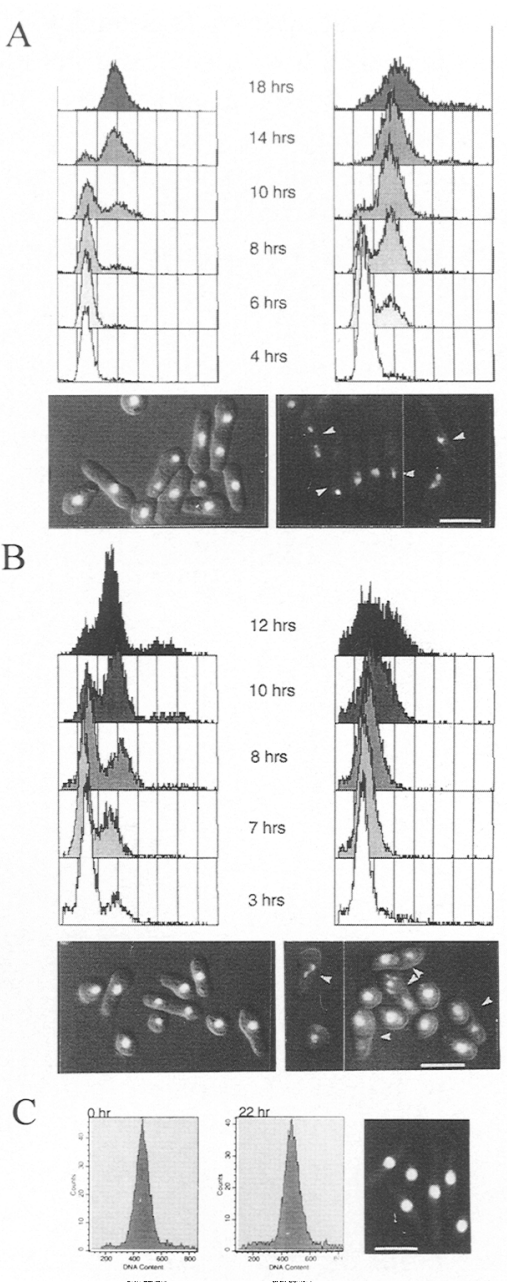

Figure 4. Deletion and overexpression of the orp1 gene. $(A)$ FACS analysis of orp $1^{+}$(left) and orp1s (right) spores germinating at $30^{\circ} \mathrm{C}$. DAPI-stained cells are shown $18 \mathrm{hr}$ after inoculation. The arrowheads point at rare cells with aberrant nuclear morphology. Bar, $10 \mu \mathrm{m}$. (B) FACS analysis of orp $1^{+}($left $)$and orp1A spores carrying the temperature-sensitive orpl protein (right), germinating at $36^{\circ} \mathrm{C}$. Smearing of the FACS profile is often seen in germinating spores undergoing cutting. DAPIstained cells are shown $10 \mathrm{hr}$ after inoculation. Arrowheads point at cells showing the cut phenotype. Bar, $10 \mu \mathrm{m} .(C)$ Overexpression of the orp $1^{+}$gene from the nmt1 promoter. (Left) FACS of cells grown in the presence of thiamine (promoter off). (Middle) FACS analysis of cells $22 \mathrm{hr}$ after induction. (Right) DAPI-stained cells $22 \mathrm{hr}$ after induction. Bar, $10 \mu \mathrm{m}$.

our conclusions drawn from the phenotype of the temperature-sensitive mutant.

We next tested the effect of overexpressing orp1 to high levels in cells. The orp1 gene was expressed using the full-strength nmt1 promoter. Cells become elongated with a $2 \mathrm{C}$ DNA content and the nuclei showed an unusual, enlarged, diffuse morphology (Fig. 4C). The cells cannot form colonies and thus high levels of the orp1 gene product are lethal. 
Regulation of orpl transcription, protein level, and intracellular localization

To investigate whether orp1 is regulated at the transcriptional level during the cell cycle, the orp1 message level was measured in cells arrested at various cell-cycle stages, using cell-cycle mutants and hydroxyurea. The stage of the cell-cycle block is shown in brackets in the following list. The level of the orp1 transcripts was the same in cells arrested with the cdc10-V50 mutant $\left(\mathrm{G}_{1}\right)$, cdc25-22 mutant $\left(\mathrm{G}_{2} / \mathrm{M}\right)$, hydroxyurea (S), nda3-KM311 mutant (metaphase), and dis3-54 mutant (anaphase) (Fig. $5 \mathrm{~A})$, indicating that there was unlikely to be any periodic changes in transcript level during the cell cycle. To follow the protein level during the cell cycle the orp1 gene was tagged on its carboxyl terminus with a triple HA tag. The orp1 gene carrying the HA tag under control of the orp1 promoter was introduced into the chromosome by gene replacement, and this strain is referred to as orp1$H A$ (Fig. 5B). The apparent molecular weight of the tagged protein is $90 \mathrm{kD}$. The protein level was monitored during the cell cycle in a $c d c 25^{t s}$ block and release experiment to synchronize the cells. The level of orp1 protein did not change significantly during the cell cycle as cells proceeded through mitosis and $\mathrm{S}$ phase, either in soluble (Fig. 5C, top) or insoluble (Fig. 5C, bottom) fractions (see Materials and Methods) of protein extracts.

To investigate the intracellular localization of orplp, exponentially growing orp1-HA cells were fixed and examined by immunofluorescence. Consistent with orplp being a component of the ORC complex, the protein was localized primarily to the nucleus with some weak staining in the cytoplasm (Fig. 5D). However, we did not detect the orp1 protein in cells undergoing mitosis (Fig. 5D, arrowed cells). This may be a result of an altered exposure of the epitope, possibly because of chromatin condensation, or a result of relocalization of the protein from the nucleus into the cytoplasm during mitosis. As a control, wild-type cells lacking orp1-HA were examined in a similar way by immunofluorescence, and although the cytoplasmic staining was detected and so is presumably nonspecific, no distinct nuclear staining was observed (Fig. 5D, inserts).

\section{orp1p interacts physically with $c d c 18 p$ and $c d c 21 p$}

To investigate whether the genetic interactions between the $c d c 18, c d c 21$, and orp1 genes result from direct protein-protein interactions, protein extracts prepared from protoplasts were immunoprecipitated with $\alpha$-HA antibody and Western blotted with $\alpha$-cdc18p (gift of $\mathrm{H}$. Nishitani, Imperial Cancer Research Fund, London, UK) and $\alpha$-cdc $21 \mathrm{p}$ antibodies (gift of D. Maiorano and S. Kearsey, Oxford University, UK). The orp1-HA cells were used, and wild-type and cig2- $H A$ cells used as controls. Extracts from all three stains were Western blotted using the $\alpha$-cdc18p (Fig. 6A, lanes 5-7) and $\alpha$-cdc2lp (Fig. 6B, lanes 5-7) antibodies. Both antibodies detected proteins of the correct molecular weight, confirming previous characterization carried out by Nishitani and Nurse
A

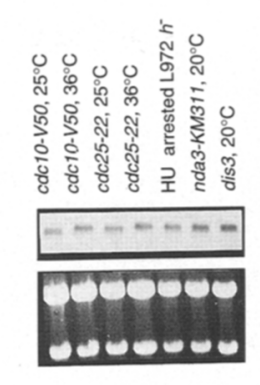

B

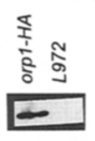

- D

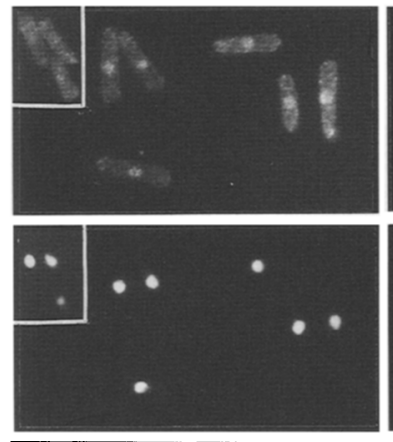

C

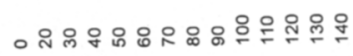
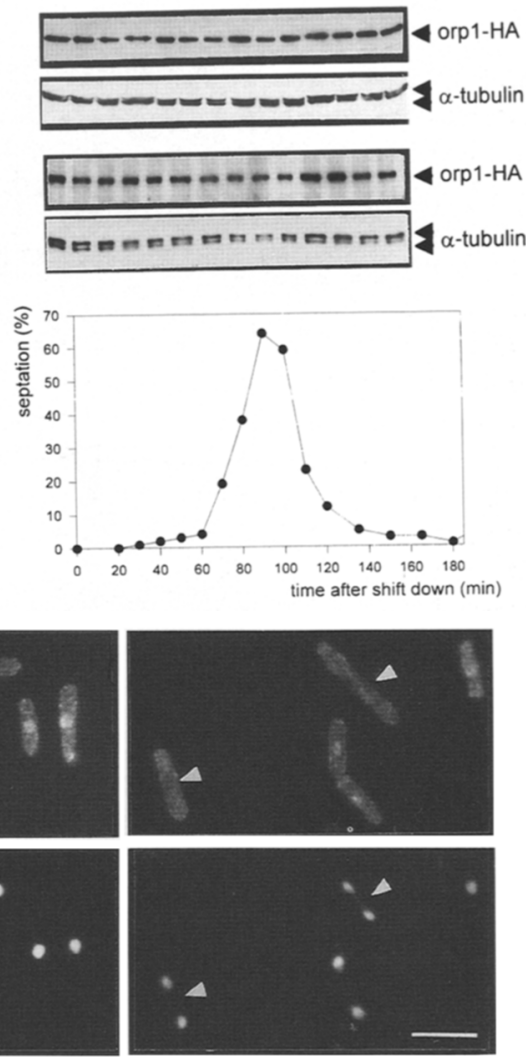

Figure 5. Cell-cycle regulation of the orp1 gene. $(A)$ Transcript level of orp1 in cell-cycle blocks (see text). The upper panel shows Northern blot analysis of the orp1 transcript, the lower panel shows the ethidium bromide-stained gel as loading control. $(B)$ Detection of the HA-tagged orpl. Protein extract was prepared from exponentially growing orp1-HA and untagged wild-type cells, run on SDS-PAGE gel, and Western blotted with $\alpha$-HA antibody. $(C)$ Level of the orpl protein during the cell cycle. $c d c 25-22$ orp1-HA cells were arrested in $\mathrm{G}_{2}$ at the restrictive temperature of $36^{\circ} \mathrm{C}$ for $4 \mathrm{hr}$, then released at $25^{\circ} \mathrm{C}$. Samples were taken every $10 \mathrm{~min}$ after the release. The graph shows the septation index during the release and $S$ phase occurs at $\sim 60-80$ min. Protein was loaded from the soluble (upper two panels) and insoluble (lower two panels) fractions of the cell extracts for Western blotting. $\alpha$-tubulin antibody was used to check even loading. (D) Immunofluorescence of exponentially growing orp1-HA cells. Upper panels show $\alpha$-HA immunofluorescence; lower panels show DAPI staining. The arrowheads point to anaphase cells. Inserts show untagged control cells. Bar, $10 \mu \mathrm{m}$.

(1995) and Maiorano et al. (1996). The extracts were also Western blotted with $\alpha$-HA antibodies that detected proteins of the correct molecular weight in extracts from the orp1-HA and cig2-HA stains but not wild-type (Fig. 6C, lanes 5-7).

The orp-HA protein was immunoprecipitated from extracts of the orp1-HA stain, and this immunoprecipitation could be competed by excess HA peptide (Fig. 6, lanes 1,2). Both cdcl8p (Fig. 6A, lane 2) and cdc21p (Fig. $6 \mathrm{~B}$, lane 2) could be detected in the orp1-HA immunoprecipitation but neither was present in the HA peptide 


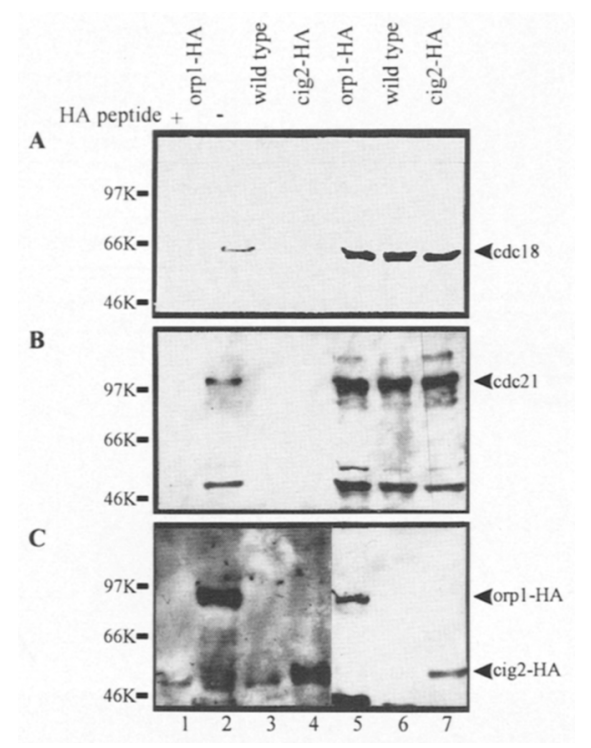

Figure 6. The orpl protein interacts with the $\operatorname{cdc} 18$ and $\operatorname{cdc} 21$ proteins. Protein extracts were prepared from exponentially growing orp1-HA (lanes 1,2,5) untagged wild-type (lanes 3,6) and cig2- $H A$ (lanes 4,7) cells. $\alpha$-HA immunoprecipitates from 10-mg soluble extracts were run in lanes $1-4.50 \mu \mathrm{g}$ soluble extracts were run in lanes 5-7. The orpl protein was immunoprecipitated both in the presence (lane 1) and in the absence (lane 2) of HA peptide. The samples were run on SDS-PAGE gel, Western blotted, and probed with $\alpha-\operatorname{cdc} 18(A) ; \alpha-\operatorname{cdc} 21(B) ;$ and $\alpha-\mathrm{HA}(C)$ antibodies.

competition control (Fig. 6A,B, lane 1). Immunoprecipitation from an extract of either wild-type or cig2-HA cells failed to bring down either cdc18p or cdc 21 p (Fig. 6, lanes 3,4$)$. These controls indicate that the complexes found between orp1-HA and cdc18p and cdc $21 \mathrm{p}$ are specific. We also attempted to do the reciprocal immunoprecipitation experiments using $\alpha$-cdcl8p antibodies, but this antibody failed to immunoprecipitate effectively. We conclude that at least some fraction of the cdc18, cdc21, and orpl proteins interact physically in vivo.

\section{Discussion}

In this paper we characterize a gene that we propose has a role at the onset of $S$ phase in fission yeast. The gene, initially called $c d c 30$, was found to be identical to the recently described orp1 gene that encodes a protein homologous to S. cerevisiae ORCl (Gavin et al. 1995; Muzi-Falconi and Kelly 1995). Given that orp1 already has been described, and the name is more consistent with the nomenclature in budding yeast where the ORC complex is best characterized, we use the name orp1 instead of $c d c 30$.

We have presented several lines of evidence that orpl acts at the $G_{1} / S$-phase transition. Analysis of temperature-sensitive and deletion mutants of orp1 show that they arrest with a 1C DNA content, prior to bulk DNA synthesis. This result is consistent with the fact that the arrest point is at or before the arrest point of the DNA synthesis inhibitor, hydroxyurea. The chromosomes prepared from the temperature-sensitive orp1-4 mutant incubated at the restrictive temperature fail to enter the gel during pulsed field gel electrophoresis, indicating that at the arrest point some topological changes of the DNA have occurred that prevent entry into the gel. The orp1-4 mutant also fails to maintain autonomously replicating episomal plasmids, indicating a defect in DNA replication. These various observations establish that orpl acts at the $G_{1} / S$-phase transition at a stage close to the initiation of DNA replication. Given the homology of orpl to ORCl, we conclude that an equivalent of the ORC complex is present in fission yeast and that this has an important role in the initiation of DNA replication. Similar conclusions have been suggested by others (Gavin et al. 1995; Muzi-Falconi and Kelly 1995; Leatherwood et al. 1996).

We also have presented evidence that orp1 interacts genetically with both $c d c 18$ and $c d c 21$, the latter showing homology to the MCM4 gene from budding yeast. The associations between orp1, $c d c 18$, and $c d c 21$ indicated by these genetic interactions have been confirmed by immunoprecipitation experiments. Immunoprecipitates of HA-tagged orplp from cell extracts contain the proteins encoded by both $c d c 18$ and $c d c 21$. In these experiments all three genes are controlled by their endogenous promotors and thus the three proteins are expressed at normal levels. Therefore the observed interactions are not a result of an artefact of overexpression. We conclude that orplp forms complexes in vivo with both p $65^{\text {cdc } 18}$ and the MCM homolog cdc 21 p, suggesting that these latter two proteins become associated with the ORC complex. Expressing p $65^{\mathrm{cdc} 18}$ to high levels is sufficient to drive cells into DNA synthesis, and the level of $\mathrm{p} 65^{\mathrm{cdc} 18}$ is periodic during the cell cycle, peaking at the $G_{1}$ - to S-phase transition (Nishitani and Nurse 1995; Muzi-Falconi et al. 1996). In contrast, we have shown here that the levels of orplp are constant during the cell cycle; orplp is also found in the nucleus, although it may undergo some change during mitosis that makes it less easy to detect by immunofluorescence. Given the physical association between orplp and $\mathrm{p} 65^{\mathrm{cdc} 18}$ reported here and the interaction between orp2p and p $65^{\text {cdc18 }}$ reported by Leatherwood et al. (1996), we propose that the increase in level of $\mathrm{p} 65^{\mathrm{cdc} 18}$ at $\mathrm{G}_{1} / \mathrm{S}$ results in p $65^{\mathrm{cdc} 18}$ becoming associated with orplp and orp2p, transiently activating a putative ORC and bringing about the initiation of DNA replication. Sometime toward the end of $S$ phase, $\mathrm{p} 65^{\mathrm{cdc} 18}$ levels drop, and thus further activation of ORC complexes is prevented. The MCM4 homolog $c d c 21$ encodes a protein that also appears to be complexed with orplp. Given its role in other systems, cdc $21 \mathrm{p}$ may be one of the components that distinguish $\mathrm{G}_{1}$ chromosomes from $\mathrm{G}_{2}$ chromosomes, allowing $G_{1}$ but not $G_{2}$ cells to undergo DNA replication. The biochemical mechanisms involved in these processes are unclear, but orplp contains a nucleotide binding site and so its action may involve ATP or GTP hydrolysis.

The proposal that associations between $\mathrm{p} 65^{\mathrm{cdc} 18}$, 
cdc21p, and ORC are important steps in the initiation of DNA replication can be incorporated into models of S-phase control presented by ourselves and others (Liang et al. 1995; Nishitani and Nurse 1995; Cocker et al. 1996; Wuarin and Nurse 1996). The association between p $65^{\mathrm{cdc} 18}$ and orplp may be necessary to generate a prereplicative complex similar to that proposed for budding yeast. The formation of this complex during $\mathrm{G}_{1}$ of budding yeast requires the CDC6 gene function (Cocker et al. 1996), which is a close homolog of $c d c 18$, and other genes may also be involved such as those encoding the MCM proteins. This process would license the DNA for replication. The generation of this complex would be the first stage in a two-step process for the initiation of DNA replication, with the second step being the onset of DNA replication. The fall in $\mathrm{p} 34^{\mathrm{cdc} 2}$ protein kinase activity as cells exit mitosis and enter $G_{1}$ would allow the association to occur and for the prereplicative complex to form on DNA origins. The complex could be similar to that found in Xenopus nuclei when $\mathrm{p} 34^{\mathrm{cdc} 2}$ is inactivated (Adachi and Laemmli 1994). After this first step is completed the complex requires phosphorylation by $\mathrm{p} 34^{\mathrm{cdc} 2}$ to bring about DNA replication, this process being the second step in the initiation of DNA replication. The rise in late $\mathrm{G}_{1}$ of $\mathrm{p} 34^{\mathrm{cdc} 2}$ protein kinase activity or of other S-phase promoting CDKs would bring about this second step and automatically prevent the formation of any further prereplicative complexes. As a consequence DNA would only be replicated once in any S phase. Such a model (Wuarin and Nurse 1996) could explain licensing and also links a number of molecules implicated in this control, including $\mathrm{p} 34^{\mathrm{cdc} 2}, \mathrm{p} 65^{\mathrm{cdc} 18}(C D C 6)$, orplp (ORC1), orp2p (ORC2), and cdc21p (MCM4).

In addition to being required for initiation of DNA replication, the orp1 gene is also required for the checkpoint pathway that prevents entry into mitosis until $S$ phase is complete. The phenotypes of both the orp 1 temperature-sensitive and deletion mutants are similar to that of $c d c 18 \Delta$, and several other mutations such as $c d c 21 \Delta, c d t 1 \Delta, c u t 5 / \mathrm{rad} 4$, and pol1s, which not only block DNA replication but also allow the cells to enter mitosis with unreplicated DNA /Saka and Yanagida 1993; Hofmann and Beach 1994; D’Urso et al. 1995; Maiorano et al. 1996). We have also shown that the $c d c 18^{\text {ts }}$ orp $1^{\text {ts }}$ and $c d c 21^{\text {ts }}$ orp $1^{\text {ts }}$ double mutants show a synthetic checkpoint defect, and that the corresponding proteins interact physically within the cell. These observations suggest that a complex involving these proteins is necessary to generate a signal that $S$ phase is in progress and as a consequence onset of mitosis should be blocked. The effects of the orp $1^{\mathrm{ts}}, c d c 18^{\mathrm{ts}}$, and $c d c 21^{\mathrm{ts}}$ single mutants are less severe than the double mutants or the corresponding null mutants. This may be because the single temperature-sensitive mutants have a less severe effect on the formation of the complex, which allows some defective DNA replication to take place and still generates a checkpoint signal that partially blocks mitosis. More severe defects produced by the double temperature-sensitive or null mutants might disturb formation of the complex more profoundly, blocking DNA replication and preventing the checkpoint signal from being generated.

We have also shown that the orp1-4 mutant is not yet committed to the mitotic cycle at its arrest point. Unlike the situation for previously identified mutants arresting pre-START, in orp1-4 cells DNA replication has been initiated at the arrest point as judged from the inability of the chromosomes to enter the gel during pulsed-field gel electrophoresis (PFGE). This observation indicates that initiation of DNA replication does not require complete commitment to the mitotic cycle because cells can still be diverted away from the mitotic cycle to undergo conjugation. The window during which cells are able to undergo conjugation appears to extend into $S$ phase. This finding suggests that the traditional view of START as an event in late $G_{1}$ that commits the cell to the mitotic cycle might require some re-evaluation. START is perhaps best considered as a window early in the cell cycle, during which cells can be diverted to undergo the alternative developmental pathway of conjugation. As cells proceed further toward S phase they complete more and more events required for progression through the cell cycle. Eventually sufficient events are completed for the cell to be put in a state that is incompatible for conjugation. Our experiments indicate that this window may be not closed until sometime just after the initiation of DNA replication. It is also possible that cells blocked using orp1-4 are initially in a committed state for the mitotic cycle but that this state is reversible and cells can eventually slip back to the pre-START state from which they can conjugate. However, operationally it is very difficult to distinguish between these different interpretations.

We conclude that orp $1 p$ is required for the onset of $S$ phase and plays a role at an early step in the initiation of DNA replication. Orplp is localized to the nucleus, consistent with a role in DNA replication, but its level remains unchanged through the cell cycle. However, orplp is found physically associated with both $\mathrm{p} 65^{\mathrm{cdc} 18}$ and cdc $21 \mathrm{p}$, and so a periodic change during the cell cycle in these protein associations could be important for controlling the onset of $S$ phase. Orplp is also required to signal to the cell that $S$ phase is in progress, implicating this early step in the initiation of DNA replication in this checkpoint control. Given that orplp is likely to be a component of ORC, these results indicate an important role for interactions between cdc18p, cdc $21 \mathrm{p}$, and ORC in controlling the initiation of DNA replication at the onset of $S$ phase and in the associated checkpoint controls.

\section{Materials and methods}

S. pombe strains and methods

All strains were derived from the wild types L972 $h^{-}$and L975 $h^{+}$. Media and growth conditions were as described by Moreno et al. (1991). The permissive and restrictive temperatures used for the heat sensitive mutants $c d c 18-K 46, c d c 21-M 68$ (Nasmyth and Nurse 1981), cdc25-22 (Fantes 1979), cdc10-129 (Nurse et al. 1976), and $c d c 10$-V50 (Marks et al. 1992) were $25^{\circ} \mathrm{C}$ and $36^{\circ} \mathrm{C}$, 
respectively. The permissive and restrictive temperatures used for the cold-sensitive mutants nda3-KM311 (Hiraoka et al. 1984) and dis3-54 (Ohkura et al. 1988) were $32^{\circ} \mathrm{C}$ and $20^{\circ} \mathrm{C}$, respectively. Standard genetic techniques, 4', 6-diamidino-2phenylindole (DAPI) staining, and cell number counting were carried out as described previously (Moreno et al. 1991). Cells were prepared for FACS analysis as described previously (Sazer and Sherwood 1990). Mating assays were carried out as described previously (Nurse and Bissett 1981) with the following modifications: Cells were grown to mid-log phase in minimal medium containing $2 \mathrm{mg} / \mathrm{ml} \mathrm{NH}_{4} \mathrm{Cl}$. They were then washed and shifted to $36^{\circ} \mathrm{C}$ in minimal medium without a $\mathrm{N}$-source. Samples were taken for FACS analysis at the time of shift to check that the cells were not accumulating in $G_{1}$ due to $N$ starvation. After $4 \mathrm{hr}$ the mating partners were mixed and shifted to $32.5^{\circ} \mathrm{C}$ to allow conjugation for $7 \mathrm{hr}$, then plated onto appropriate media to determine the number of diploid cells. Immunofluorescence was carried out as described (Moreno et al. 1991). Cells were fixed with methanol. TAT1 antibodies (gift from Keith Gull, Manchester University, UK) and CY3 conjugated goat antimouse secondary antibodies (Sigma) were used for tubulin staining. 12CA5 antibodies (Boehringer) and CY3 conjugated goat antimouse secondary antibodies were used to examine the localization of orp1-HA.

\section{Cloning and sequencing}

The genomic clone of orp $1^{+}$was obtained by transforming the orp1-4 ura4-D18 $h^{-}$strain with a genomic library in pUR19 provided by A.M. Carr (Barbet et al. 1992). Transformants were plated on minimal medium, incubated at $25^{\circ} \mathrm{C}$ overnight, and then shifted to $36^{\circ} \mathrm{C}$. Plasmids were reisolated from 12 colonies which contained three overlapping clones. Sequencing was carried out using the Sequenase II and $\Delta$ Taq cycle sequencing kits United States Biochemical. Alignments were carried out using the GAP program of the GCG package of sequence software.

\section{PFGE}

Agarose plugs were prepared as described by Kelly et al. (1993). PFGE was carried out in $0.6 \%$ chromosomal grade agarose gel (BioRad), using a BioRad CHEF-DRII. The gel was run for $72 \mathrm{hr}$ at $50 \mathrm{~V}$ with a switch time of $30 \mathrm{~min}$, in $0.5 \times$ TAE.

\section{Deletion and spore germination}

A fragment carrying the orp1:ura $4^{+}$construct with $1 \mathrm{~kb}$ of flanking sequence was transformed into a diploid strain ade6M210/ade6-M216 ura4-D18/ura4-D18 $\mathrm{h}^{+} / \mathrm{h}^{-}$. Stable transformants were isolated and gene replacement was confirmed by Southern analysis. Diploid cultures of the strain carrying the deletion and the wild-type control ade6-M210/ade6-M216 ura $4^{+} /$ura4-D18 $\mathrm{h}^{+} / \mathrm{h}^{-}$were sporulated in minimal medium lacking a nitrogen source. Spores were germinated in minimal medium at $30^{\circ} \mathrm{C}\left(\operatorname{orp} 1^{+} /\right.$orp $\left.1 \Delta\right)$ or $36^{\circ} \mathrm{C}\left(\operatorname{orp} 1^{\text {ts }} /\right.$ orp $\left.1 \Delta\right)$.

\section{HA tagging of orp1}

A restriction site for Notl was introduced before the STOP codon of the orp1 ORF and was used to insert a fragment encoding three copies of the HA tag. A genomic fragment containing orp1-HA was transformed into the orp 1-4 mutant and transformants were incubated at $36^{\circ} \mathrm{C}$. Integration was confirmed by Southern analysis.
Preparation of protein extracts, immunoprecipitations, and Western blots

The soluble and insoluble fractions were prepared as described previously (Nishitani and Nurse 1995). For immunoprecipitations the cells were protoplasted with Novozyme in $0.65 \mathrm{M} \mathrm{KCl}$, washed in $1 \mathrm{M}$ sorbitol and lysed in HB buffer. HB buffer contains $60 \mathrm{~mm} \beta$-glycerophosphate, $15 \mathrm{~mm}$ p-nitrophenylphosphate, $25 \mathrm{~mm}$ MOPS (pH 7.2), $1 \%$ Triton, $15 \mathrm{~mm} \mathrm{MgCl}_{2}, 15 \mathrm{~mm}$ EGTA, $1 \mathrm{~mm}$ DTT, $0.1 \mathrm{~mm}$ sodium-vanadate, $1 \mathrm{~mm}$ PMSF, 20 $\mathrm{mg} / \mathrm{ml}$ leupeptin, and $20 \mathrm{mg} / \mathrm{ml}$ aprotinin. The lysate was incubated on ice for $30 \mathrm{~min}$, then centrifuged at $15000 \mathrm{rpm}$ using an Eppendorf microfuge for $20 \mathrm{~min}$ at $4^{\circ} \mathrm{C}$. Ten milligrams of the supernatant was used for immunoprecipitations. orp1-HA was immunoprecipitated with 12CA5 Mab cross-linked to Dynebeads coated with $\alpha$-mouse secondary antibody (Dynal). Protein extracts and immunoprecipitates were electrophoresed using an $8 \%$ SDS-polyacrylamide gel. Dilutions of the antibodies were $1: 2000$ for $\alpha$-cdc18, 1:500 for $\alpha$-cdc21, and 1:1000 for $\alpha$-HA, and proteins were detected using ECL (Amersham).

\section{Acknowledgments}

We thank members of the Cell Cycle Lab, especially Jaime Correra and Hideo Nishitani, for helpful discussions and advice, and thank Buzz Baum, Julian Blow, Erik Boye, and Kirsten Skarstad for comments on the manuscript. We would like to thank $\mathrm{H}$. Okayama for sharing unpublished results, and D. Maiorano and S. Kearsey for their generous gift of $\alpha-\operatorname{cdc} 21$ and H. Nishitani for $\alpha$-cdc18 antibodies. The Imperial Cancer Research Fund and the Human Frontier Science Program provided financial support. B.G. was supported by postdoctoral fellowships from the Royal Society and from the European Molecular Biology Organization.

The publication costs of this article were defrayed in part by payment of page charges. This article must therefore be hereby marked "advertisement" in accordance with 18 USC section 1734 solely to indicate this fact.

\section{References}

Adachi, Y., and U.K. Laemmli. 1994. Study of the cell cycledependent assembly of the DNA pre-replication centres in Xenopus egg extracts. EMBO J. 13: 4153-4164.

Barbet, N., W.J. Muriel, and A.M. Carr. 1992. Versatile shuttle vectors and genomic libraries for use with Schizosaccharomyces pombe. Gene 114: 59-66.

Bell, S.P. and B. Stillman. 1992. ATP-dependent recognition of eukaryotic origins of DNA replication by a multiprotein complex. Nature 357: 128-134.

Bell, S.P., R. Kobayashi, and R. Stillman. 1993. Yeast origin recognition complex functions in transcription silencing and DNA replication. Science 262: 1844-1849.

Bell, S.P., J. Mitchell, J. Leber, R. Kobayashi, and B. Stillman. 1995. The multidomain structure of Orclp reveals similarity to regulators of DNA replication and transcriptional silencing. Cell 83: 563-568.

Caligiuri, M. and D. Beach. 1993. Sct 1 functions in partnership with $\mathrm{Cdcl0}$ in a transcription complex that activates cell cycle START and inhibits differentiation. Cell 72: 607-619.

Carpenter, P.B., P.R. Mueller, and W.G. Dunphy. 1996. Role for a Xenopus ORC2-related protein in controlling DNA replication. Nature 379: 357-360.

Chong, J.P., H.M. Mahbubani, C.Y. Khoo, and J.J. Blow. 1995. Purification of an MCM-containing complex as a component 
of the DNA replication licensing system. Nature 375: 418421.

Chong, J.P., P. Thommes, and J.J. Blow. 1996. The role of MCM/ $\mathrm{P} 1$ proteins in the licensing of DNA replication. Trends Biochem. Sci. 21: 102-106.

Cocker, J.H., S. Piatti, C. Santocanale, K. Nasmyth, and J.F. Diffley. 1996. An essential role for the CDC6 protein in forming the prereplicative complexes of budding yeast. $\mathrm{Na}$ ture 379: 180-182.

Correa-Bordes, J. and P. Nurse. 1995. p2 $5^{\text {ruml }}$ orders S phase and mitosis by acting as an inhibitor of the p34 ${ }^{\text {cdc2 }}$ mitotic kinase. Cell 83: 1001-1009.

Coué, M., S.E. Kearsey, and M. Méchali. 1996. Chromatin binding, nuclear localization and phosphorylation of Xenopus cdc2 1 are cell-cycle dependent and associated with the control of initiation of DNA replication. EMBO J. 15: 10851097.

Coxon, A., K. Maundrell, and S.E. Kearsey. 1992. Fission yeast $\operatorname{cdc} 21^{+}$belongs to a family of proteins involved in an early step of chromosome replication. Nucleic Acids Res. 20: 5571-5577.

Dalton, S. and L. Whitbread. 1995. Cell cycle-regulated nuclear import and export of $\mathrm{Cdc} 47$, a protein essential for initiation of DNA replication in budding yeast. Proc. Natl. Acad. Sci. 92: 2514-2518.

Diffley, J.F. and J.H. Cocker. 1992. Protein-DNA interactions at a yeast replication origin. Nature 357: 169-172.

Diffley, J.F., J.H. Cocker, S.J. Dowell, and A. Rowley. 1994. Two steps in the assembly of complexes at yeast replication origins in vivo. Cell 78: 303-316.

D'Urso, G., B. Grallert, and P. Nurse. 1995. DNA polymerase alpha, a component of the replication initiation machinery, is essential for the checkpoint coupling $\mathrm{S}$ phase to mitosis in fission yeast. I. Cell Sci. 108: 3109-3119.

Fantes, P. 1979. Epistatic gene interactions in the control of division in fission yeast. Nature 279: 428-430.

Foss, M., F.J. McNally, P. Laurenson, and J. Rine. 1993. Origin recognition complex (ORC) in transcriptional silencing and DNA replication in S. cerevisiae. Science 262: 1838-1844.

Fox, C.A., S. Loo, A. Dillin, and J. Rine. 1995. The origin recognition complex has essential functions in transcriptional silencing and chromosomal replication. Genes \& Dev. 9: 911-924.

Fujita, M., T. Kiyono, Y. Hayashi, and M. Ishibashi. 1996. hCDC47, a human member of the MCM family - Dissociation of the nucleus-bound form during $\mathrm{S}$ phase. I. Biol. Chem. 271: 4349-4354.

Gavin, K.A., M. Hidaka, and B. Stillman. 1995. Conserved initiator proteins in eukaryotes. Science 270: 1667-1671.

Gossen, M., D.T.S. Pak, S.K. Hansen, J.K. Acharya, and M.R. Botchan. 1995. A Drosphila homolog of the yeast origin recognition complex. Science 270: 1674-1677.

Hayles, J. and P. Nurse. 1995. A pre-start checkpoint preventing mitosis in fission yeast acts independently of p34 ${ }^{\text {cdc2 }}$ tyrosine phosphorylation. EMBO J. 14: 2760-2771.

Hayles, J., D. Fisher, A. Woollard, and P. Nurse. 1994. Temporal order of $\mathrm{S}$ phase and mitosis in fission yeast is determined by the state of the p34 ${ }^{c d c 2}$-mitotic B cyclin complex. Cell 78: 813-822.

Hennessy, K.M., C.D. Clark, and D. Botstein. 1990. Subcellular localization of yeast CDC46 varies with the cell cycle. Genes \& Dev. 4: 2252-2263.

Hiraoka, Y., T. Toda, and M. Yanagida. 1984. The nda $3^{+}$gene of fission yeast encodes beta-tubulin: A cold-sensitive nda3 mutation reversibly blocks spindle formation and chromosome movement in mitosis. Cell 39: 349-358.
Hofmann, J.F. and D. Beach. 1994. $c d t 1$ is an essential target of the Cdc10/Sct1 transcription factor: Requirement for DNA replication and inhibition of mitosis. EMBO J. 13: 425-434.

Hogan, E. and D. Koshland. 1992. Addition of extra origins of replication to a minichromosome suppresses its mitotic loss in $c d c 6$ and cdc14 mutants of Saccharomyces cerevisiae. Proc. Natl. Acad. Sci. 89: 3098-3102.

Kelly, T.J., G.S. Martin, S.L. Forsburg, R.J. Stephen, A. Russo, and P. Nurse. 1993. The fission yeast $c d c 18^{+}$gene product couples S phase to START and mitosis. Cell 74: 371-382.

Kimura, H., N. Nozaki, and K. Sugimoto. 1994. DNA polymerase alpha associated protein $\mathrm{P} 1$, a murine homolog of yeast MCM3, changes its intranuclear distribution during the DNA synthetic period. EMBO I. 13: 4311-4320.

Krude, T., C. Musahl, R.A. Laskey, and R. Knippers. 1996. Human replication proteins hCdc21, hCdc 46 and $\mathrm{P} 1 \mathrm{Mcm} 3$ bind chromatin uniformly before S-phase and are displaced locally during DNA replication. J. Cell Sci. 109: 309-318.

Kubota, Y., S. Mimura, S. Nishimoto, H. Takisawa, and H. Nojima. 1995. Identification of the yeast MCM3 related protein as a component of Xenopus DNA replication licensing factor. Cell 81: 601-609.

Leatherwood, I., A. LopezGirona, and P. Russell. 1996. Interaction of cdc 2 and cdc1 8 with a fission yeast ORC2-like protein. Nature 379: 360-363.

Liang, C., M. Weinreich, and B. Stillman. 1995. ORC and Cdc6p interact and determine the frequency of initiation of DNA replication in the genome. Cell 81: 667-676.

Loo, S., C.A. Fox, J. Rine, R. Kobayashi, B. Stillman, and S.P. Bell. 1995. The origin recognition complex in silencing, cell cycle progression and DNA replication. Mol. Biol. Cell 6: 741-757.

Lowndes, N.F., C.J. McInerny, A.L. Johnson, P.A. Fantes, and L.H. Johnston. 1992. Control of DNA synthesis genes in fission yeast by the cell cycle gene $c d c 10^{+}$. Nature 355: 449453.

Madine, M.A., C.Y. Khoo, A.D. Mills, C. Musahl, and R.A. Laskey. 1995. The nuclear envelope prevents reinitiation of replication by regulating the binding of MCM3 to chromatin in Xenopus egg extracts. Curr. Biol. 5: 1270-1279.

Maine, G.T., P. Sinha, and B.K. Tye. 1984. Mutants of S. cerevisiae defective in the maintenance of minichromosomes. Genetics 106: 365-385.

Maiorano, D., G.B. Van Assendelft, and S.E. Kearsey. 1996. Fission yeast cdc21, a member of the MCM protein family, is required for onset of $S$ phase and is located in the nucleus throughout the cell cycle. EMBO J. 15: 861-872.

Marks, J., C. Fankhauser, A. Reymond, and V. Simanis. 1992. Cytoskeletal and DNA structure abnormalities result from bypass of requirement for the $c d c 10$ start gene in the fission yeast Schizosaccharomyces pombe. J. Cell Sci. 101: 517528.

Martin-Castellanos, C., K. Labib, and S. Moreno. 1996. B-type cyclins regulate $G_{1}$ progression in fission yeast in opposition to the p25 $5^{\text {rum1 }} \mathrm{cdk}$ inhibitor. EMBO J. 15: 839-849.

Micklem, G., A. Rowley, J. Harwood, K. Nasmyth, and J.F. Diffley. 1993. Yeast origin recognition complex is involved in DNA replication and transcriptional silencing. Nature 366: 87-89.

Moreno, S. and P. Nurse. 1994. Regulation of progression through the Gl phase of the cell cycle by the ruml ${ }^{+}$gene. Nature 367: 236-242.

Moreno, S., A. Klar, and P. Nurse. 1991. Molecular genetic analysis of fission yeast Schizosaccharomyces pombe. Methods Enzymol. 194: 795-823.

Muzi-Falconi, M. and T.J. Kelly. 1995. Orplp, a member of the 
cdc18/CDC6 family of S phase regulators, is homologous to a component of the origin recognition complex. Proc. Natl. Acad. Sci. 92: 12475-12479.

Muzi-Falconi, M., G.W. Brown, and T.J. Kelly. 1996. $c d c 18^{+}$ regulates initiation of DNA replication in Schizosaccharomyces pombe. Proc. Natl. Acad. Sci. 93: 1566-1570.

Nasmyth, K. and P. Nurse. 1981. Cell division cycle mutants altered in DNA replication and mitosis in the fission yeast Schizosaccharomyces pombe. Mol. Gen. Genet. 182: 119124.

Nishitani, H. and P. Nurse. 1995. p65 ${ }^{c d c 18}$ plays a major role controlling the initiation of DNA replication in fission yeast. Cell 83: 397-405.

Nurse, P. and Y. Bissett. 1981. Gene required in Gl for commitment to cell cycle and in G2 for control of mitosis in fission yeast. Nature 292: 558-560.

Nurse, P., P. Thuriaux, and K. Nasmyth. 1976. Genetic control of the cell division cycle in the fission yeast Schizosaccharomyces pombe. Mol. Gen. Genet. 146: 167-178.

Ohkura, H., Y. Adachi, N. Kinoshita, O. Niwa, T. Toda, and M. Yanagida. 1988. Cold-sensitive and caffeine-supersensitive mutants of the Schizosaccharomyces pombe dis genes implicated in sister chromatid separation during mitosis. $E M B O$ J. 7: 1465-1473.

Saka, Y. and M. Yanagida. 1993. Fission yeast $\mathrm{cut}^{+}$, required for S phase onset and $M$ phase restraint, is identical to the radiation-damage repair gene $\mathrm{rad}^{+}$. Cell 74: 383-393.

Sazer, S. and S.W. Sherwood. 1990. Mitochondrial growth and DNA synthesis occur in the absence of nuclear DNA replication in fission yeast. J. Cell Sci. 97: 509-516.

Tanaka, K., K. Okazaki, N. Okazaki, T. Ueda, A. Sugiyama, H. Nojima, and H. Okayama. 1992. A new $c d c$ gene required for $S$ phase entry of Schizosaccharomyces pombe encodes a protein similar to the $c d c 10^{+}$and SWI4 gene products. EMBO I. 11: 4923-4932.

Todorov, I.T., A. Attaran, and S.E. Kearsey. 1995. BM28, a human member of the MCM2-3-5 family, is displaced from chromatin during DNA replication. J. Cell Biol. 129: 14331445.

Wuarin, J. and P. Nurse. 1996. Regulating S phase: CDKs, licensing and proteolysis. Cell 85: 785-787.

Yan, H., A.M. Merchant, and B.K. Tye. 1993. Cell cycle-regulated nuclear localization of MCM2 and MCM3, which are required for the initiation of DNA synthesis at chromosomal replication origins in yeast. Genes \& Dev. 7: 2149-2160. 


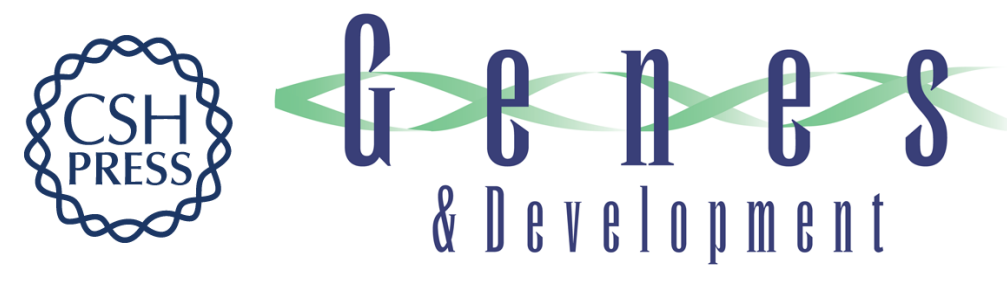

\section{The ORC1 homolog orp1 in fission yeast plays a key role in regulating onset of S phase.}

B Grallert and P Nurse

Genes Dev. 1996, 10:

Access the most recent version at doi:10.1101/gad.10.20.2644

References

This article cites 58 articles, 18 of which can be accessed free at: http://genesdev.cshlp.org/content/10/20/2644.full.html\#ref-list-1

\section{License}

Email Alerting

Receive free email alerts when new articles cite this article - sign up in the box at the top Service right corner of the article or click here.

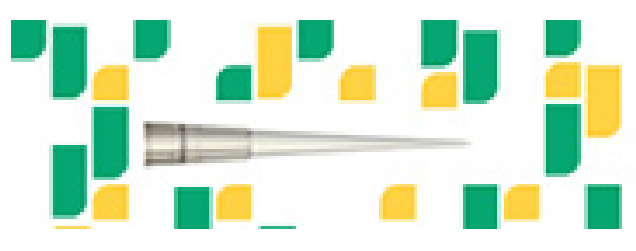

